\title{
Radiographic Accuracy in Scaphoid Waist Fractures
}

\author{
Richard C Rooney ${ }^{1 *}$ and Du Preez Smith ${ }^{2}$ \\ ${ }^{1}$ Orthopedic Surgeon at the Seattle Regenerative Medicine Center, Seattle, Washington USA \\ ${ }^{2}$ Medical Student, Royal College of Surgeons, Ireland
}

Received: 制 October 16, 2018 Published: 制 October 23, 2018

*Corresponding author: Richard C Rooney, Seattle, Washington USA

\section{Abstract}

Objectives: We compared CT scanning and radiographic imaging to determine the relationship between measurements of displacement and angulation of the fracture.

Design: X-ray review.

Methods: All patients with acute scaphoid fractures treated at our hospital in a 4-year period that had a CT scan and plain radiographs were evaluated. The maximum displacement seen on either AP or lateral X-rays was measured as well as the amount of palmar flexion through the fracture as seen on the lateral X-ray. The differences were calculated and the mean of the sum of the differences was calculated.

Results: 103 patients radiographic files were evaluated and 43 were found to have CT scans through the longitudinal axis of the scaphoid as well as AP and lateral plain radiographs taken within one week of the CT in acute fractures. The average displacement seen on the CT was $1.85 \mathrm{~mm}$ with an average of 50.9 degrees of palmar flexion through the fracture. The average displacement and angulation on the plain radiographs were $.93 \mathrm{~mm}$ and 33.2 degrees respectively. The mean difference in displacement and angulation between the CT scan and plain radiographs was $1.39 \mathrm{~mm}(\mathrm{p}=0.003)$ and 17.9 degrees $(\mathrm{p}=0.013)$ respectively. These were statistically significant using paired t-test comparison.

Conclusion: We believe that the accurate assessment of scaphoid fractures is essential to ensure the most appropriate treatment is rendered. We feel that CT scanning should be used to evaluate all acute scaphoid fractures to ensure that the most reliable determination of displacement can be made, and the most effective treatment rendered.

\section{Introduction}

Radiographs are routinely used to diagnose and evaluate scaphoid fracture displacement and angulation [1-9]. The amount of angulation and displacement is used to determine whether or not a patient would benefit from non-operative or operative management [10-12]. The accuracy of plain radiographs is often taken for granted and has not been validated with other imaging modalities that are more accurately utilized for fracture displacement and angulation. We compared CT scanning and radiographic imaging to determine the relationship between measurements.

\section{Materials and Methods}

All patients with acute scaphoid fractures treated at our hospital over a 4-year period that had a CT scan and plain radiographs were evaluated. The maximum displacement and angulation of the scaphoid fracture was measured in the sagittal plane (Figure 1) using the dorsal cortical angle (Figure 2) $[13,14]$. The maximum displacement seen on either AP or lateral X-rays was measured as well as the amount of palmar flexion through the fracture as seen on the lateral X-ray. The differences were calculated and the mean of the sum of the differences was calculated.

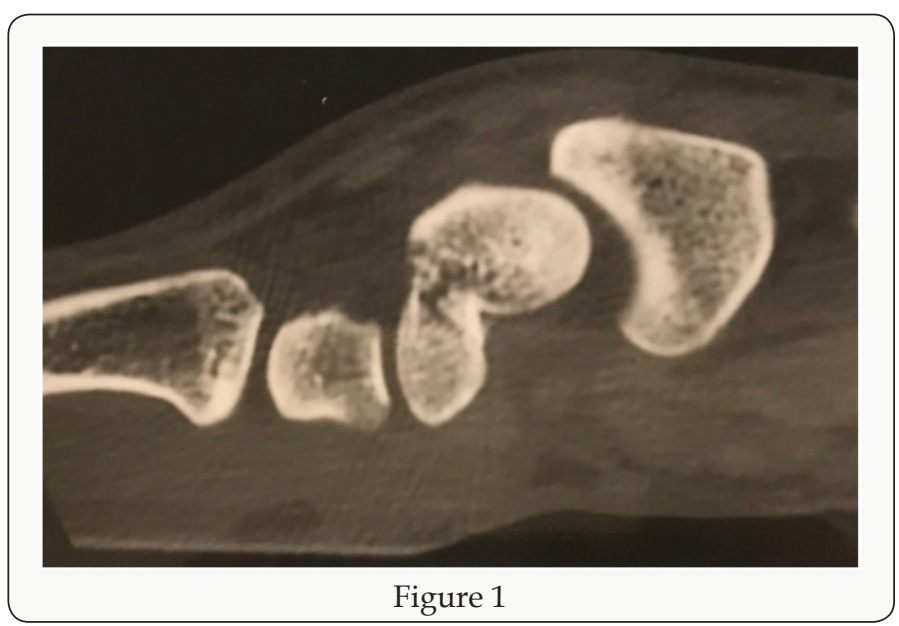

Results

103 patients' radiographic files were evaluated and 43 were found to have CT scans through the longitudinal axis of the scaphoid 
as well as AP and lateral plain radiographs taken within one week of the CT in acute fractures. The average displacement seen on the CT was $1.85 \mathrm{~mm}$ with an average of 50.9 degrees of palmar flexion through the fracture. The average displacement and angulation on the plain radiographs were $.93 \mathrm{~mm}$ and 33.2 degrees respectively. The mean difference in displacement and angulation between the CT scan and plain radiographs was $1.39 \mathrm{~mm}(\mathrm{p}=0.003)$ and 17.9 degrees $(p=0.013)$ respectively. These were statistically significant using paired t-test comparison.

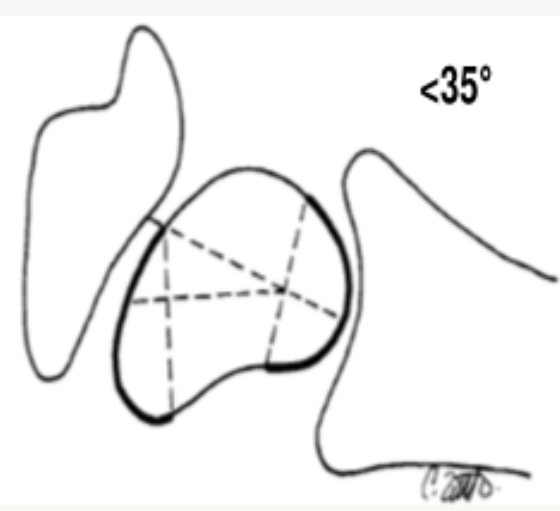

Figure 2: Intrascaphoid angle. A perpendicular line is drawn to the proximal and distal articular surfaces and the resulting angle is measured.

\section{Discussion}

Scaphoid fractures are one of the most troublesome injuries about the wrist. The propensity for suboptimal outcomes with these injuries should make the treating physician particularly suspicious when dealing with wrist injuries that may involve the scaphoid. Radiographic determination of displacement and angulation of scaphoid fractures is quite difficult at times. Displacement and angulation of $1 \mathrm{~mm}$ and $60-70$ degrees is generally accepted as indications for operative stabilization of scaphoid fractures $[15,16]$. Hence, it is extremely important to evaluate the scaphoid using the most accurate modality available.

\section{Conclusion}

In our series of patients, we have found a significant discrepancy in the amount of displacement and angulation between plain X-rays and CT scanning. Based on this data we recommend CT scanning for all scaphoid fractures that have displacement and angulation. The CT scan will better delineate the fracture characteristics and facilitate pre-operative planning.

\section{References}

1. Berna JD (1998) Scaphoid fractures and non-unions: A comparison between panoramic radiography and plain x-rays. J Hand Surg B 23(3): 328-331.

2. Cooney WP, Dobyns JH, Linscheid RL (1980) Fractures of the Scaphoid: A rational approach to treatment. CORR 149: 90-97.

3. Dias JJ, Thompson J, Barton NJ, Gregg PJ (1990) Suspected Scaphoid Fractures. JBJS(Br) 72: 98-101.

4. Larsen CT (1991) Observer variability in measurements of carpal bone angles on lateral wrist radiographs. J Hand Surg 16(5): 893-898.

5. Roolker W (1996) Carpal box radiography in suspected scaphoid fracture. JBJS (Br) 78(4): 535-539.

6. Roolker W (1997) Experimental evaluation of scaphoid X-series, carpal box radiographs, planar tomography, computed tomography, and magnetic resonance imaging in the diagnosis of scaphoid fracture. J Trauma 42(2): 247-253.

7. Saunders WE (1988) Evaluation of the humpback scaphoid by computed tomography in the longitudinal axial plane of the scaphoid. J Hand Surg 13(2): 182-187.

8. Tiel-van Buul MM (1992) Diagnosing scaphoid fractures: Radiographs cannot be used as a gold standard. Injury 23(2): 77-79.

9. Tiel-van Buul MM (1992) Radiography of the Carpal Scaphoid. Inv Radiology 27(11): 954-959.

10. Cautilli GP, Wehbe MA (1991) Scapho-lunate distance and cortical ring sign. J Hand Surg 16(3): 501-503.

11. Hindman BW, Kulik WJ, Lee G, Avolio RE (1989) Occult Fractures of the Carpals and Metacarpals: Demonstration by CT. AJR 153(3): 523-529.

12. Vender MI (1987) Degenerative change in symptomatic scaphoid nonunion. J Hand Surg 12(4): 514-519.

13. Bain GI (1995) Longitudinal computed tomography of the scaphoid: A new technique. Skel Rad 24(4): 271-273.

14. Bain GI (1998) Measurement of the scaphoid humpback deformity using longitudinal computed tomography: Intra and interobserver variability using various measurement techniques. J Hand Surg 23(1): 76-81.

15. Cooney WP, Dobyns JH, Linscheid RL (1980) Fractures of the Scaphoid: A rational approach to treatment. CORR 149: 90-97.

16. Weber ER (1980) Biomechanical implications of scaphoid waist fractures. CORR 149: 83-89. (c) (P) This work is licensed under Creative BY Commons Attribution 4.0 License

To Submit Your Article Click Here: Submit Article

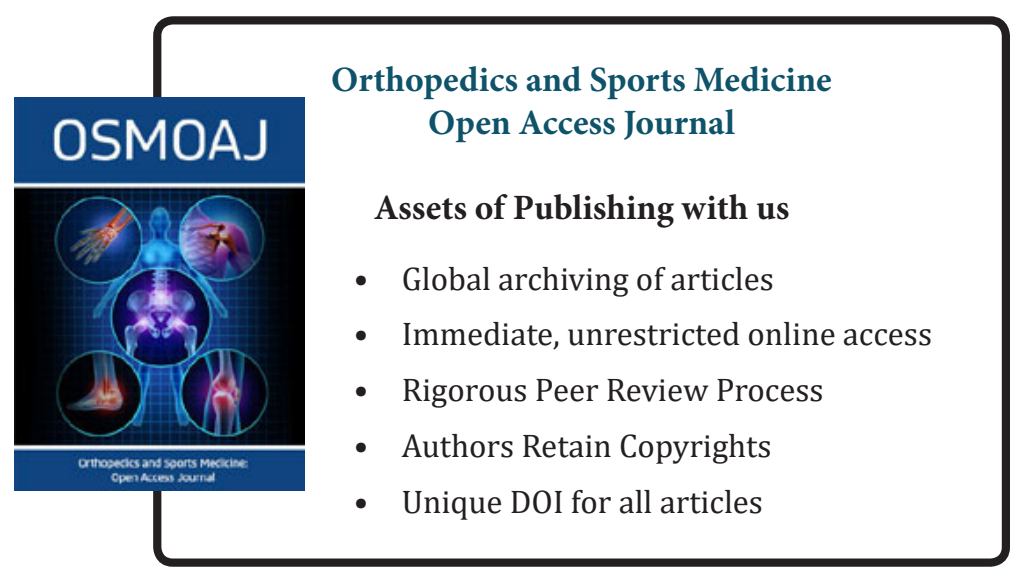

